

А.М. Цалиев

\title{
О РАСШИРЕНИИ РОЛИ СУБЪЕКТОВ РОССИЙСКОЙ ФЕДЕРАЦИИ ВО ВНУТРЕННЕЙ ГОСУДАРСТВЕННОЙ ПОЛИТИКЕ
}

\begin{abstract}
Аннотация: В статье рассматривается проблема расширения роли субъектов Российской Федерации во внутренней государственной политике, одним из важнейших способов разрешения которой признается оптимальное распределение предметов ведения и полномочий между Российской Федерацией и ее субъектами, органами государственной власти различного уровня. Предлагается ряд конструктивных мер по укреплению роли субъектов Российской Федерации.

Ключевые слова: Юриспрудениия, предметы ведения, полномочия, субъекты РФ, договор, соглатение, внутренняя государственная политика, разграничение, Конституичя РФ, закон
\end{abstract}

B формировании и развитии внутренней политики Российской Федерации в области государственного строительства, законодательства, защиты прав и свобод человека и гражданина, в социально-экономической сфере, культуре и пр. все большую роль играют ее субъекты. Она тем более усиливается, когда согласование интересов центра и регионов происходит на основе научно обоснованного, осознанного и проверенного практикой оптимального распределения предметов ведения и полномочий между Российской Федерацией и ее субъектами. Конечно, такое распределение не может быть статичным, раз и навсегда установленным даже на уровне конституционно-правовых положений, а уж тем более в государственной политике - явлении весьма динамичном. Федерализм - одно из ее проявлений в сфере государственного строительства и являет собой динамичное, развивающееся, функционирующее явление, имеющее исторический, политический, идеологический, национальный, культурный, экономический, юридический и др. аспекты.

Политика, право и государство, как, собственно, и другие социальные явления и процессы, взаимосвязаны между собой, поэтому, с учетом происходящих в мире процессов глобализации, размывания и игнорирования норм права, развала государств, а то и целых империй, стали меняться не только межгосударственные, но и внутренние государственные отношения. В СССР идеологической основой этого стала так называемая «горбачевская» пере-

\footnotetext{
${ }^{1}$ См.: Гумашвили Л.Э. Конституционно-правовое понятие и содержание взаимоотношений федерального центра и субъектов РФ // Конституционное и муниципальное право. 2010. № 11. С. 21.
}

стройка, которую мы, в отличие от ныне преуспевающих стран, начали не с научно-обоснованного анализа состояния советского общества, его социально-экономической основы - фундамента, а с революционного внедрения гласности, свободы и демократии, что в конечном итоге стало основной причиной развала огромного государства.

В значительной мере такой финал был закономерен, поскольку без решения фундаментальных социальных и экономических проблем общества, к тому же, в отсутствие достаточного исторического опыта самостоятельного федеративного государственного строительства, нельзя было резко переходить от тоталитарной системы управления к демократической. Еще в начале ХХ в. П.И. Новгородцев подчеркивал, что для достижения демократии нужен народ, созревший «до управления самим собой, сознающий свои права и уважающий чужие, понимающий свои обязанности и способный к самоограничению. Такая высота политического сознания никогда не дается сразу, она приобретается долгим и суровым опытом жизни. И чем сложнее и выше задачи, которые ставятся перед государством, тем более требуется для этого политическая зрелость народа, содействие лучших сторон человеческой природы и напряжение всех нравственных сил»².

К сожалению, всего этого политического и духовного арсенала не оказалось не только в самой «горбачевской команде», но и в ее ресурсе. В связи с этим стал реальностью процесс распада территориальной целостности самой Российской Федерации в уже новых ее границах. И здесь нельзя не сказать об огромном значении, которое

\footnotetext{
${ }^{2}$ Новгородиев П.И. Об общественном идеале. М., 1911-1913.
} C. 548 . 
сыграл Федеративный договор 1992 года ${ }^{3}$ На это вполне обоснованно обращают внимание в политической и юридической литературе. Об этом я могу судить не только по печати, но и изнутри, как участник подготовки Договора.

Оценивая политикуроссийских властей в начале 90 -хг.г., Президент Российской Федерации В.В. Путин отмечал: «В начале 90-х центр многое отдал на откуп регионам. Это была сознательная, хотя отчасти и вынужденная политика. Но она помогла руководству России добиться тогда главного и, думаю, была обоснованна, она помогла удержать Федерацию в ее границах» ${ }^{4}$. Федеративный договор 1992 года был первым демократическим документом, обеспечивающим единство страны и во многом остановившим «парад суверенитетов»5. В то же время, он признал конституционным принцип федерализма, который предусматривает и признает, что в государстве, наряду с общими интересами, признаются и гарантируются интересы субъектов Федерации. Федерализм - это территориальный каркас демократии, поскольку он основан на уважении и поддержке политического, культурного, национального многообразия общества, способен реально стимулировать процессы самоорганизации многонационального и многоконфессинального российского общества, вовлекая огромные массы населения в управление государством на всех уровнях, это сознательный выбор современных и эффективных технологий управления страной, которые позволяют максимально использовать уникальный потенциал многообразия регионов единого государства. ${ }^{6}$

Принятие Конституции Российской Федерации 1993 года стало началом нового этапа в построении реального российского федерализма, демократизации государственной власти, предусматривающей федеральный и региональный уровни публичной власти, осуществляющие взаимодействие через административные, правовые и договорные механизмы.

Политико-правовой основой сохранения целостности Российской Федерации стало предусмотренное в Договоре и Конституции Российской Федерации расширение роли и статуса ее субъектов во внутренней и внешней политике государства на основе научно обоснованного принципа

\footnotetext{
${ }^{3}$ Он был подписан 31 марта 1992 года, одобрен постановлением Съезда народных депутатов от 10 апреля 1992 года и включен в состав Конституции РФ 1978 Законом РФ от 21 апреля 1992 года.

${ }^{4}$ Послание Президента Российской Федерации Федеральному Собранию Российской Федерации «Государство Россия. Путь к эффективному государству (О положении в стране и основных направлениях внутренней и внешней политики государства)». M., 2000. C. 25-26.

${ }^{5}$ См.: Абдулатипов Р.Г. О федеративной и региональной политике Российского государства. М., 1995. С. 14.

${ }^{6}$ См.: Проект «Концепции государственной политики по разграничению предметов ведения и полномочий между... уровнями власти» // Журнал «Казанский федералист». 2002. № 1.
}

субсидиарности и конституционно-правовых положений распределения предметов ведения и полномочий между центром и его регионами. Эти и другие принципы и положения урегулированы в Федеральном законе от 6 октября 1999 г. № 184-Ф3 «Об общих принципах организации (представительных) и исполнительных органов государственной власти субъектов Российской Федерации».

Политическую модернизацию государственных и общественных институтов, предложенную в последнее время Президентом Российской Федерации, можно назвать новым этапом развития федеративных отношений в России, где во внутренней и внешней политике, наряду с укреплением федеральных органов государственной власти, расширяется роль регионов за счет оптимального распределения полномочий между федеральными и региональными органами власти по предметам совместного ведения, передачи субъектам Российской Федерации функций, с которыми они сами могут справиться. Иначе, как правильно отмечается в литературе, чрезмерное доминирование принципа централизма во взаимоотношениях между Российской Федерацией и ее субъектами в условиях модернизации может создать иллюзию эффективности такой модели. Признавая значимость и ценность централистской политики, необходимо постепенно модернизировать федеративные отношения в России без социально-политических кризисов. ${ }^{8} \mathrm{C}$ этой целью «вовлечение в процесс модернизации максимального числа субъектов Российской Федерации является объективной потребностью. Субъекты Российской Федерации должны быть признаны как важнейшие конституционные институты развития страны... Необходимость радикально модернизировать федеративную политику с обязательным признанием российских регионов одним из локомотивов поступательного развития страны объективно требует более высокого уровня участия субъектов Федерации в модернизационном процессе»9.

Обязательным условием успеха стратегических преобразований является наведение порядка в отношениях между федеральными и региональными органами власти. Отсутствие четкого разграничения полномочий, а также работоспособного механизма взаимодействия между уровнями власти приводит нас к большим экономических и социальным потерям, - говорится еще в Послании 2001 г. Президента Российской Федерации Федеральному Собранию.

\footnotetext{
${ }^{7}$ Применение этого принципа требует при распределении полномочий брать в расчет прежде всего способность органов того или иного уровня эффективно решать в конкретных исторических условиях задачи, стоящие перед Федерацией.

${ }^{8}$ См.: Юсубов Е.С. Модернизация федеративных отношений и субъекты Российской Федерации // Конституционное и муниципальное право. 2010. № 8. С. 24.

${ }^{9}$ Там же.
} 


\section{Право и политика $1(157) \cdot 2013$}

Законодательную базу разграничения предметов ведения и полномочий между федеральными и региональными органами государственной власти составляют, прежде всего, ст.ст. 5, 11, 71, 72, 73, 76, 78 Конституции Российской Федерации, федеральные законы, законы субъектов РФ, договоры, соглашения.

Тесная взаимосвязь предметов ведения и полномочий во многом предопределила вывод Конституционного Суда Российской Федерации о недопустимости перераспределения не только предметов ведения, закрепленных конституционно, но и полномочий, составляющих этот предмет. Исходя из федеративной природы Российского государства, федеральный законодатель не вправе закреплять за Федерацией весь объем полномочий по конкретному предмету ведения. ${ }^{10}$ Это положение неоднократно формулировалось в качестве правовой позиции Конституционного Суда РФ. Так, в Постановлении от 3 ноября 1997 г. № 15-П установлено, что если определенные вопросы отнесены Конституцией РФ к совместному ведению Федерации и ее субъектов, то их решение не может находиться ни в исключительной компетенции Федерации, ни в исключительной компетенции ее субъектов. В Постановлении Конституционного Суда РФ от 11 апреля 2000 г. № 6-П сформулировано, что из федеративной природы взаимоотношений Российской Федерации и ее субъектов вытекает недопустимость произвольного присвоения органами государственной власти Российской Федерации всей полноты полномочий по предметам совместного ведения, т.е. без учета интересов субъектов РФ и места их органов власти в системе публичной власти.

В ходе проводимой федеративной реформы органам государственной власти субъектов Российской Федерации переданы более пятидесяти полномочий по предметам совместного ведения, которые они обязаны выполнять за счет собственного бюджета. Однако при этом в законах субъектов должны быть предусмотрены объемы осуществления соответствующих полномочий и порядок их финансирования, иначе они не могут быть реализованы. Поэтому нет оснований для восприятия ситуации таким образом, что полномочия возлагаются на них в прежнем, неизменном виде. ${ }^{11}$ Помимо этого, со второй половины

\footnotetext{
${ }^{10}$ См.: Крылов Б.С. Концепция развития законодательства в сфере федеративных, региональных и национальных отношений // В кн.: Концепции развития российского законодательства. С. 45; Варламова Н.B. Современный российский федерализм: конституционная модель и политико-правовая динамика. С. 50; Черепанов В.A. Конституционно-правовые основы разделения государственной власти между Российской Федерацией и ее субъектами: Монография. С. 211-216.

${ }^{11}$ См.: Шувалов И.И. Совершенствование законодательства субъектов Российской Федерации в связи с реформой федеративных отношений и местного самоуправления // Журнал российского права. 2004. № 9. С. 5-7.
}

2000-го года все чаще происходит процесс обратной передачи субъектам федеральных полномочий по предметам совместного ведения путем их делегирования с передачей федеральных субвенций.

Процесс делегирования полномочий из центра в регионы Ю.А. Тихомировым оценивается положительно, поскольку он дает расширение партнерства и более гибкое выполнение функций с учетом конкретной обстановки и ее быстрых изменений. Исполнители делегированных полномочий, по его мнению, лучше стимулируются и чувствуют свою ответственность. ${ }^{12}$

Расширение роли субъектов во внутренней политике Российской Федерации возможно также за счет расширения полномочий региональных органов государственной власти в рамках совместных договоров $u$ соглашений. Согласно пункту 2 ст. 26.7 Федерального закона № 184-Ф3 «Заключение договоров о разграничении полномочий допускается только в случае, если это обусловлено экономическими, географическими и иными особенностями субъекта Российской Федерации, и в той мере, в которой указанными особенностями определено иное, чем это установлено федеральными законами, разграничение полномочий». Что же касается соглашений, то, как отмечают специалисты, они «помогли решить ряд вопросов развития российских территорий, скоординировать и рационализировать использование ресурсов субъекта Федерации, исходя из его особенностей и не ущемляя общероссийские интересы, уточнить полномочия государственных органов». ${ }^{13}$ Законодательной основой такого процесса является конституционная норма о том, что разграничение предметов ведения и полномочий между федеральными и региональными органами государственной власти осуществляется Конституцией, Федеративным и иными договорами о разграничении предметов ведения и полномочий (ч. 1 ст. 11).

Несмотря на вышеизложенное, проблема заключения юридически обоснованных договоров и соглашений между различными органами публичной власти является актуальной во всех федеративных государствах, поскольку задачи, стоящие перед ними, постоянно обновляются. Поэтому зафиксировать на все времена полномочия разных уровней власти в полном и исчерпывающем объеме невозможно. Не зря через некоторое время в России продолжился поиск эффективного решения данной проблемы. Чтобы исключить возможность противоречия

\footnotetext{
${ }^{12}$ Тихомиров Ю.А. Административное право и процесс. М., 2001. C. 175 .

13 Чертков А.Н. Об общих принципах организации законодательных (представительных) и исполнительных органов государственной власти субъектов Российской Федерации. Постатейный комментарий к Федеральному закону. М., 2006. С. 353.
} 
Конституции Российской Федерации и федеральному законодательству договоров между федеральными и региональными органами государственной власти по вопросам распределения полномочий, правовой формой этих договоров ныне признается федеральный закон, на что указал Конституционный Суд Российской Федерации в своем Постановлении от 9 января 1998 г. № 1-П.

С введением процедуры, в соответствии с которой договорный способ регулирования разграничения полномочий может быть реализован только при условии «подтверждающего» законодательного регулирования, федеральный закон стал, по сути, единственной (в смысле практически применимой) формой разграничения федеральных и региональных полномочий. При этом «федеральными законами... не могут передаваться, исключаться, иным образом перераспределяться установленные Конституцией Российской Федерации предметы ведения Российской Федерации и соответствующие им полномочия федеральных органов государственной власти» ${ }^{14}$.

Таким образом, с учетом фактического содержания федерального законодательства использование договоров как правовой формы разграничения полномочий может диктоваться лишь политическими целями, о чем свидетельствует последний договор с Татарстаном. ${ }^{15}$ К настоящему времени, в рамках продолжающейся федеративной реформы, в общей сложности были приняты около 20 федеральных законов, наиболее предметно регулирующих договоры о разграничении полномочий.

Соглашения о разграничении полномочий между органами исполнительной власти по конкретным предметам совместного ведения Российской Федерации и субъектов являются составной частью договоров о разграничении предметов ведения и полномочий в соответствии с Указом Президента Российской Федерации и сложившейся договорной практикой. Такие соглашения о взаимной передаче осуществления части полномочий между федеральными органами исполнительной власти и органами исполнительной власти субъектов установлены в ст. 78 (ч.ч. 2 и 3) Конституции Российской Федерации как правовой инструмент оптимизации управления в Российской Федерации.

\footnotetext{
${ }^{14}$ См.: Постановление Конституционного Суда РФ «По делу о проверке конституционного отдельных положений Конституции Республики Алтай и Федерального закона «Об общих принципах организации законодательных (представительных) и исполнительных органов государственной власти субъектов Российской Федерации» от 7 июня 2000 г. // Вестник Конституционного Суда РФ. 2000. № 5.

${ }^{15}$ См.: Федеральный закон «Об утверждении Договора о разграничении предметов ведения и полномочий между органами государственной власти Российской Федерации и органами государственной власти Республики Татарстан» от 24 июля 2007 г. // Собрание законодательства РФ. 2007. № 31. Ст. 3996.
}

Договоры и соглашения о разграничении предметов ведения и полномочий между различными уровнями государственной власти позволяют:

- достичь решения сложнейших задач в области государственного строительства;

- установить контроль за правовым регулированием субъектами Федерации вопросов, связанных с реализацией ими полномочий по предметам совместного ведения, в том числе и неурегулированных федеральным законодательством;

- реализовать конституционное право субъектов Федерации передавать предметы своего собственного ведения в совместное в случае отсутствия у них финансовых и иных возможностей самостоятельно осуществлять полномочия в данных сферах общественных отношений;

- определять приоритеты в законодательном регулировании предметов совместного ведения на основе закрепления в федеральных законах и иных правовых актах норм, оправдавших себя в практике договорного процесса.

Договорный процесс оценивается специалистами поразному и, разумеется, каждый из них приводит соответствующие аргументы, со многими из которых трудно не согласиться. Но при всей важности и убедительности различных оценок договорных отношений между Российской Федерацией и ее субъектами сегодня это устоявшийся политический и правовой процесс, игнорировать который невозможно. Поэтому необходимо воспользоваться опытом германской правовой школы, согласно которому равновесие между унитарными и федеративными элементами, поддерживающие всю систему, состоит в том, что федерации предоставлена наиболее существенная часть законодательной, а землям - административной компетенции. Процесс заключения договоров следует использовать именно для определения пределов административной компетенции субъектов Российской Федерации. М.А. Сахле рассматривает договор в качестве политического пропуска к возможности решать экономические задачи и, вместе с тем, в качестве инструмента совершенствования федеративных отношений. ${ }^{16}$

Сфера разграничения совместного ведения остается одной из актуальных политико-правовых проблем. Безусловно, как было сказано, она расширяет возможности регионов во внутренней политике Российской Федерации, но, с другой стороны, вызывает опасения со стороны субъектов в нарушении конституционного принципа их равноправия перед федеральным центром, что вовсе не способствует стабилизации социально-политической обстановки в стране. Не зря на одном из заседаний Парламента Республики Северная Осетия-Алания группа депутатов предложила внести предложение о том, что если

${ }^{16}$ Сахле М.А. Организационные формы взаимодействия Президента РФ с субъектами РФ // Законодательство. № 6. 1998. С. 34-47. 


\section{Право и политика $1(157) \cdot 2013$}

более половины субъектов направляет отрицательный отзыв на законопроект, касающийся сферы совместного ведения, то его следует снять с дальнейшего рассмотрения Государственной Думой.

Представляется, что в рамках законодательного поля для наиболее полного достижения общественных и государственных интересов необходимо продолжить процесс заключения договоров и соглашений. Тем более что в рамках модернизации нашей страны такая практика начала складываться. Например, Республикой Северная ОсетияАлания за последние годы заключены соглашения о социально-экономическом, научно-техническом и культурном сотрудничестве с Московской областью, Ростовской областью, Волгоградской областью, Краснодарским краем, городом Москва, городом Санкт-Петербург и другими субъектами. Содержание этих соглашений подробно раскрывается в постановлениях правительств соответствующих субъектов Российской Федерации.

Соглашения заключены также между Правительством Республики Северная Осетия-Алания и различными отраслевыми органами Правительства Российской Федерации. Они направлены на улучшение социальноэкономической ситуации, повышение роли республики во внутренней политике Российской Федерации.

Вместе с тем данная работа во многом продолжает носить спонтанный характер. До сих пор нет единой сформировавшейся научной концепции государственной политики по разграничению предметов ведения и полномочий между федеральными и региональными уровнями власти. Не зря на заседании Государственного Совета еще 21 июля 2006 г., посвященном вопросу стратегического планирования социально-экономического развития территорий Российской Федерации, А.Г. Хлопонин отметил: «...Россия сегодня не обеспечена самым главным - правовой основой для формирования единой системы регионального планирования и взаимоувязки федеральных и региональных аспектов. Это для такой большой страны, как Россия, конечно же, парадокс. То есть реализуемая региональная политика складывается не по плану, а как получится... Фактически реализуемая в России региональная политика является не результатом осмысленного планирования, а, скорее, суммой случайных последствий от реализации самых разных документов преимущественно отраслевой направленности. Так, конечно, дальше продолжаться не может» ${ }^{17}$. В этой связи он указал на необходимость решения следующих задач:

\footnotetext{
${ }^{17}$ См.: Выдержки из стенографического отчета о заседании Государственного совета Российской Федерации «О механизмах взаимодействия федеральных и региональных органов исполнительной власти при разработке программ комплексного социальноэкономического развития регионов» // Государственная власть и местное самоуправление. 2006. № 8 .
}

1) внести назревшие коррективы в разграничение предметов ведения и полномочий между Российской Федерацией и субъектами Российской Федерации и, в то же время, обеспечить развитие их кооперации, широкого сотрудничества между ветвями власти и управления по вертикали и горизонтали;

2) усовершенствовать функционирование вертикали власти, обеспечить оптимизацию учета интересов как Федерации в целом, так и ее субъектов;

3) продолжить отладку законодательной деятельности в субъектах Российской Федерации, завершить законодательное оформление региональной политики путем принятия Концепции региональной политики, а также решить все еще имеющиеся проблемы несоответствия между Конституцией Российской Федерации, федеральными законами и конституциями (уставами) и иными нормативными правовыми актами субъектов Российской Федерации и др.

Для расширения роли субъектов во внутренней государственной политике необходимо «обеспечить эффективную децентрализацию полномочий между уровнями публичной власти в пользу субъектов Российской Федерации и местного самоуправления, а также необходимые источники их финансирования» ${ }^{18}$.

С учетом анализа результатов научной и практической работы, программных выступлений государственных деятелей по вопросу разграничения полномочий между различными органами публичной власти можно предложить следующие меры, направленные на расширение роли регионов во внутренней политике Российской Федерации:

- ускорить разработку и принятие соответствующей программы, предусматривающей расширение роли субъектов во внутренней государственной политике;

- ускорить разработку и принятие федеральных законов, регулирующих общие положения по предметам совместного ведения, с тем чтобы субъекты РФ имели возможность, с учетом своих специфических особенностей, более подробно регулировать вопросы своих полномочий;

- предусмотреть организационные и правовые формы участия органов исполнительной власти субъектов в разработке вышеназванных законов;

- организовать и законодательно закрепить систему межбюджетных отношений, обеспечивающих финансирование полномочий, не входящих в прямую компетенцию субъекта РФ;

- предусмотреть нормативное положение о том, что если более половины субъектов направляет отрицательный отзыв на законопроект, касающийся сферы совместного ведения, то его следует снимать с дальнейшего рассмотрения Государственной Думой;

\footnotetext{
${ }^{18}$ Медведев Д.А. Бюджетное послание Федеральному Собранию Российской Федерации от 29 июня 2011 г. «О бюджетной политике в 2012-2014 годах».
} 
- организовать межведомственную Комиссию при Президенте Российской Федерации по подготовке договоров о разграничении полномочий между органами государственной власти Российской Федерации и органами государственной власти субъектов Российской Федерации.

\section{Библиография:}

1. Гумашвили Л.Э. Конституционно-правовое понятие и содержание взаимоотношений федерального центра и субъектов РФ // Конституционное и муниципальное право. 2010. № 11. С. 21.

2. Новгородцев П.И. Об общественном идеале. М., 19111913. С. 548.

3. Послание Президента Российской Федерации Федеральному Собранию Российской Федерации «Государство Россия. Путь к эффективному государству (О положении в стране и основных направлениях внутренней и внешней политики государства)». М., 2000. C. 25-26.

4. Абдулатипов Р.Г. О федеративной и региональной политике Российского государства. М., 1995. С. 14.

5. Проект «Концепции государственной политики по разграничению предметов ведения и полномочий между... уровнями власти» // Журнал «Казанский федералист». 2002. № 1.

6. Юсубов Е.С. Модернизация федеративных отношений и субъекты Российской Федерации // Конституционное и муниципальное право. 2010. № 8. C. 24.

7. Крылов Б.С. Концепция развития законодательства в сфере федеративных, региональных и национальных отношений // В кн.: Концепции развития российского законодательства. С. 45;

8. Варламова Н.В. Современный российский федерализм: конституционная модель и политико-правовая динамика. С. 50;

9. Черепанов В.А. Конституционно-правовые основы разделения государственной власти между Российской Федерацией и ее субъектами: Монография. С. 211-216.

10. Шувалов И.И. Совершенствование законодательства субъектов Российской Федерации в связи с реформой федеративных отношений и местного самоуправления // Журнал российского права. 2004. № 9. С. 5-7.

11. Тихомиров Ю.А. Административное право и процесс. М., 2001. С. 175.

12. Чертков А.Н. Об общих принципах организации законодательных (представительных) и исполнительных органов государственной власти субъектов Российской Федерации. Постатейный комментарий к Федеральному закону. М., 2006. С. 353.
13. Постановление Конституционного Суда РФ «По делу о проверке конституционного отдельных положений Конституции Республики Алтай и Федерального закона «Об общих принципах организации законодательных (представительных) и исполнительных органов государственной власти субъектов Российской Федерации» от 7 июня 2000 г. // Вестник Конституционного Суда РФ. 2000. № 5 .

14. Федеральный закон «Об утверждении Договора о разграничении предметов ведения и полномочий между органами государственной власти Российской Федерации и органами государственной власти Республики Татарстан» от 24 июля 2007 г. // Собрание законодательства РФ. 2007. № 31. Ст. 3996.

15. Сахле М.А. Организационные формы взаимодействия Президента РФ с субъектами РФ // Законодательство. № 6. 1998. С. 34-47.

16. Выдержки из стенографического отчета о заседании Государственного совета Российской Федерации «О механизмах взаимодействия федеральных и региональных органов исполнительной власти при разработке программ комплексного социально-экономического развития регионов» // Государственная власть и местное самоуправление. 2006. № 8.

17. Медведев Д.А. Бюджетное послание Федеральному Собранию Российской Федерации от 29 июня 2011 г. «О бюджетной политике в 2012-2014 годах».

\section{References (transliteration):}

1. Gumashvili L.E. Konstitutsionno-pravovoe ponyatie i soderzhanie vzaimootnosheniy federal'nogo tsentra $i$ sub'ektov RF // Konstitutsionnoe i munitsipal'noe pravo. 2010. № 11. S. 21.

2. Novgorodtsev P.I. Ob obshchestvennom ideale. M., 1911-1913. S. 548.

3. Abdulatipov R.G. O federativnoy i regional'noy politike Rossiyskogo gosudarstva. M., 1995. S. 14.

4. Yusubov E.S. Modernizatsiya federativnykh otnosheniy i sub'ekty Rossiyskoy Federatsii // Konstitutsionnoe i munitsipal'noe pravo. 2010. № 8. S. 24.

5. Krylov B.S. Kontseptsiya razvitiya zakonodatel'stva v sfere federativnykh, regional'nykh i natsional'nykh otnosheniy // V kn.: Kontseptsii razvitiya rossiyskogo zakonodatel'stva. S. 45;

6. Varlamova N.V. Sovremennyy rossiyskiy federalizm: konstitutsionnaya model' i politiko-pravovaya dinamika. S. 50;

7. Cherepanov V.A. Konstitutsionno-pravovye osnovy razdeleniya gosudarstvennoy vlasti mezhdu Rossiyskoy Federatsiey i ee sub'ektami: S. 211-216. 


\section{Право и политика $1(157) \cdot 2013$}

8. Shuvalov I.I. Sovershenstvovanie zakonodatel'stva sub'ektov Rossiyskoy Federatsii v svyazi s reformoy federativnykh otnosheniy i mestnogo samoupravleniya // Zhurnal rossiyskogo prava. 2004. № 9. S. 5-7.

9. Tikhomirov Yu.A. Administrativnoe pravo i protsess. M., 2001. S. 175.

10. Chertkov A.N. Ob obshchikh printsipakh organizatsii zakonodatel'nykh (predstavitel'nykh) i ispolnitel'nykh organov gosudarstvennoy vlasti sub'ektov Rossiyskoy Federatsii. Postateynyy kommentariy k Federal'nomu zakonu. M., 2006. S. 353.

11. Sakhle M.A. Organizatsionnye formy vzaimodeystviya Prezidenta RF s sub'ektami RF // Zakonodatel'stvo. № 6. 1998. S. 34-47.

12. Medvedev D.A. Byudzhetnoe poslanie Federal'nomu Sobraniyu Rossiyskoy Federatsii ot 29 iyunya 2011 g. «O byudzhetnoy politike v 2012-2014 godakh». 